LBNL-52520

\title{
Comparison of Predicted and Derived Measures of Volatile Organic Compounds inside Four Relocatable Classrooms Due to Identified Interior Finish Sources
}

\author{
Alfred T. Hodgson, Derek G. Shendell, William J. Fisk, and Michael G. Apte
}

June 2003

\begin{abstract}
Indoor exposures to toxic and odorous volatile organic compounds (VOCs) are of general concern. Recently, VOCs in portable or relocatable classrooms (RCs) have received particular attention. However, very little was known about indoor environmental quality (IEQ) and the sources, composition, and indoor concentrations of VOCs in RCs.
\end{abstract}

This project task focused on developing and demonstrating a process for selecting interior finish materials for RCs that have relatively low impacts with respect to their emissions of toxic and odorous VOCs. This task was part of a larger project to demonstrate the potential for simultaneous improvements in IEQ and energy efficiency in four new RCs equipped both with a continuously ventilating advanced heating, ventilating, and air conditioning system (HVAC) and a standard HVAC system. These HVACs were operated on alternate weeks. One RC per pair was constructed with standard interior finish materials, and the other included alternate interior materials identified in our prior laboratory study to have low VOC emissions. The RCs were sited in side-by-side pairs at two elementary schools in distinct northern California climate zones. Classroom VOC emission rates $\left(\mathrm{mg} \mathrm{hr}^{-1}\right)$ and concentrations were predicted based on VOC emission factors $\left(\mu \mathrm{g} \mathrm{m}^{-2} \mathrm{hr}^{-1}\right)$ measured for individual materials in the laboratory, the quantities of installed materials and design ventilation rates. Predicted emission rates were compared to values derived from classroom measurements of VOC concentrations and ventilation rates made at pre-occupancy, eight weeks, and 27 weeks. Predicted concentrations were compared to measured integrated VOC indoor minus outdoor concentrations during school hours in the fall cooling season with the advanced HVAC operated. These measured concentrations also were compared between standard and material-modified RCs.

Our combined laboratory and field process proved effective by correctly predicting that IEQ impacts of material VOC emissions would be minor when RCs were ventilated at or above code- 
minimum requirements. Assuming code-minimum ventilation rates are maintained, the benefits attributable to the use of alternate interior finish materials in RC's constructed by the manufacturer associated with this study are small, implying that it is not imperative to use such alternative finishing materials. However, it is essential to avoid materials that can degrade IEQ, and the results of this study demonstrate that laboratory-based material testing combined with modeling and field validation can help to achieve that aim.

\section{Introduction and Background}

Indoor exposures to toxic volatile organic compounds (VOCs) are of general concern. In California and elsewhere in the U.S., schools have become a focus of complaints regarding children's potential exposures to biological and toxic, airborne, chemical contaminants including formaldehyde. Odorous VOCs also are of potential concern because they can adversely affect people's acceptance of indoor environments and possibly their performance. A few studies have been conducted to identify and quantify the sources of toxic and odorous VOCs in new manufactured houses (Hodgson et al., 2000 and 2002). Much less is known about the sources, composition, and concentrations of VOCs of concern in schools, particularly new relocatable classrooms (RCs, also termed modular or portable classrooms).

California is rapidly constructing new schools and additional classrooms. The State's public schools for grades K-12 currently enroll approximately six million students, with more than 200,000 staff. The projected rapid population growth of school aged children and class size reduction policies require increased classroom space. Relocatable classrooms provide school districts with a quick, convenient and relatively low cost way to add or replace classrooms. Since 1986, California legislation has mandated 20 percent or more of new classrooms be RCs.

Ensuring new RCs are both energy efficient and provide healthy environments for students and staff is an important goal for the State. The task reported on here was part of a larger project designed to address these twin issues. Specifically, the overall project goals were to engineer and evaluate an improved RC design incorporating an energy efficient heating, ventilation, and air conditioning (HVAC) system, with the potential to consume less energy and provide 
improved indoor air and environmental quality (IEQ) as compared to the currently available RC models.

This project task focused on developing and demonstrating a process for selecting interior finish materials for RCs that have relatively low impacts with respect to their emissions of toxic and odorous VOCs, including formaldehyde and acetaldehyde. The task involved the participation of a large northern California manufacturer of conventional RCs and two northern California school districts. It was conducted as a two-stage study with both laboratory- and field-based components. The laboratory study was documented in a previous report (Hodgson et $a l ., 2001)$ and is further discussed herein. Its objectives were to characterize the emissions of VOCs from standard materials used to finish the interiors of RCs produced by this manufacturer and to identify alternate, non cost-prohibitive, easy to clean and maintain materials to reduce VOC concentrations in new classrooms. The results of the laboratory study were used to develop specifications for four new RCs. Two were designed with standard interior finishes, and two were designed with alternate materials. In the selection of alternate materials, emphasis was placed on reducing the potential concentrations of VOCs that appear on California agency lists of toxic compounds.

The four classrooms were constructed in summer 2001. They were installed in pairs at elementary schools in the two participating school districts for use starting with the fall semester. The classrooms were to be occupied by third and fourth grade children who spend most of their time in their homeroom. The classrooms were each uniquely equipped with two independent HVAC systems, a conventional compressor-based unit and an advanced system that was the subject of the energy efficient ventilation project task. The classrooms were instrumented to measure a number of IEQ and energy use parameters. The impacts of the two HVAC systems on energy consumption and IEQ were investigated over the fall and spring semesters using a case crossover design; each RC served as its own control, as the different HVAC systems were operated on alternate weeks. The study included the weekly measurement of school day integrated indoor and outdoor VOC concentrations.

The objectives of this project task were to determine: 1) if indoor VOC concentrations in the new classrooms were predicted with reasonable accuracy from the results of the laboratory study of material VOC emissions; and 2) if concentrations of VOCs of concern were reduced through 
the process we devised for interior material selection. These objectives were addressed in two ways. Experiments were conducted in the classrooms prior to first occupancy and during the fall and spring semesters to derive whole-building VOC emission rates. These values were compared between standard and source-modified classrooms and to classroom emission rates predicted from the laboratory study results. In addition, VOC concentrations measured during occupied hours in the fall semester with the advanced HVAC system operational were similarly compared between classrooms and to predicted concentrations.

\section{Methods}

\section{Laboratory Study Methods}

The methods employed in the laboratory-based study are summarized here and are described in detail elsewhere (Hodgson et al., 2001).

The RC manufacturer provided samples of most standard classroom interior finish materials. These were either taken from stock or collected from the production facility. Samples of several standard materials were purchased. Material manufacturers provided samples of the alternate materials, which were specified to be newly manufactured. There were 17 material samples in total encompassing floor coverings, tackable wall panels and acoustical ceiling panels. Smallscale test specimens, with typical, exposed, surface area dimensions of $15 \mathrm{~cm}$ by $15 \mathrm{~cm}$ were prepared for each material sample.

The emissions of VOCs from the test specimens were individually determined following the guidance of ASTM D 5116-97 (ASTM, 1997). Specimens were initially conditioned at typical indoor conditions for ten days prior to emission testing. At the end of the conditioning period, a test specimen was transferred to a 10.5-L stainless steel chamber. The chamber was maintained at $23 \pm 1^{\circ} \mathrm{C}$ temperature with a $0.059 \pm 0.003 \mathrm{~m}^{3} \mathrm{~h}^{-1}$ inlet flow rate of high purity nitrogen preconditioned to $50 \pm 5$ percent relative humidity. Samples for the analysis of VOCs and aldehydes were collected from the chamber exhaust at 96-h elapsed time. Analytical methods for VOCs and aldehydes were identical to those given below for the classroom study.

The chamber samples were qualitatively analyzed to identify all VOCs emitted by each material. Then, the samples were quantitatively analyzed for odorous chemicals and chemicals of concern listed by any of three California programs regulating and/or assessing health risks of 
toxic chemicals (i.e., Chemicals with Established Noncancer Chronic Toxicity Reference

Exposure Levels, Substances identified as Toxic Air Contaminants, and Safe Drinking Water and Toxic Enforcement Act of 1986; Table 4, Hodgson et al., 2001).

Material VOC emission rates, emission factors, and predicted classroom concentrations were calculated from the chamber results.

\section{Classroom Study Methods}

The methods employed in the classroom-based study are summarized here and are described in detail elsewhere (Shendell et al., 2002a-b).

The field study was conducted at two elementary schools in two separate northern California school districts, designated School Districts (SDs) A and B. Working with the RC manufacturer and the school districts, we developed specifications for four new RCs, which were produced in late summer 2001 and installed at the schools for occupancy by the fall 2001 semester. The two source-modified classrooms were finished with alternate tackable wall panels, ceiling panels, and carpet (one school) as described in Laboratory Study Results. Each classroom was equipped with two separate ventilation systems; a standard 10 SEER Heat Pump Air Conditioner (HPAC) system and an advanced indirect/direct evaporative cooling with hydronic heating (IDEC) system. A standard and a modified classroom were sited adjacent to each other at each of the two schools. These have been designated SDA-A, modified classroom at SD A (formerly designated RC 2 in Hodgson et al., 2001, 2002); SDA-B, standard classroom at SD A (formerly RC 1c); SDB-A, modified classroom at SD B (formerly RC 4); and SDB-B, standard classroom at SD B (formerly RC 3c).

Throughout the course of the field study, each classroom was alternated on a weekly basis between the HPAC and IDEC systems. The changeovers were coordinated, i.e., the two classrooms at each school were always operating on the same system. The classroom teachers had control of the fan and temperature settings for both systems. The study was conducted from August 2001 through March 2002 during eight and nine weeks in the fall cooling and winter heating seasons, respectively.

School-day integrated air samples ( $\sim 7$ hours) were collected for aldehydes and VOCs inside each classroom and outdoors at each school during mid-week. VOC and aldehyde active 
sampling systems, located within outdoor enclosures, consisted of timer-controlled peristaltic pumps collecting single or duplicate VOC samples on multisorbent tubes and aldehyde samples on treated silica-gel cartridges. The sampling media were located inside each classroom $\sim 2.25 \mathrm{~m}$ above the floor and $0.7 \mathrm{~m}$ away from the back wall, and outside facing away from the standard HVAC system air inlet $\sim 1 \mathrm{~m}$ from the back wall of a classroom. Flow rates of the sampling systems, $\sim 150 \mathrm{~cm}^{3} \mathrm{~min}^{-1}$ for aldehyde sampling and $\sim 5-6 \mathrm{~cm}^{3} \mathrm{~min}^{-1}$ for VOC sampling, were measured in the morning within 30 minutes after the start and in the afternoon. Duplicate indoor aldehyde and VOC samples, at least 10\% overall for each sample type, were collected. Field blanks, $10 \%$ overall for each sample type, also were collected.

Samples were analyzed within two weeks of collection. The chemical analysis method for VOC samples was gas chromatography/mass spectrometry with thermal desorption sample injection. For aldehyde samples, the method was extraction of the analyte derivatives from the cartridges with acetonitrile followed by analysis with high performance liquid chromatography and UV detection. The standard deviations (i.e., precision) for the analyses were calculated by analysis of variance from the sample-pair data. The lower limit of quantitation (LOQ) for each compound was calculated as the $95 \%$ confidence interval of the precision. For compounds with measured outdoor concentrations, the LOQs for indoor minus outdoor concentrations were determined by propagation of uncertainties. Values below the LOQ were assigned one-half the LOQ in the data files for statistical analyses. The criteria for selecting target VOCs were the same as those used in the laboratory study.

For complete details of the sampling, sample handling, calibration, analytical, and data handling procedures, refer to Hodgson et al. (2001) and Shendell et al. (2002a).

Separate studies of VOC emission rates were conducted prior to occupancy and eight and 27 weeks after first occupancy. These studies were performed with the classrooms unoccupied. For the pre-occupancy sampling event, the classrooms were operated with the HPAC systems, which were positioned so the fans were on continuously. The systems had not been adjusted to their final settings at this time. For the subsequent two sampling events, the classrooms were operated with the advanced IDEC systems, which were on continuously. The IDEC systems were run over night. Ventilation rates were measured in the early evening and VOC samples were collected on the following morning prior to class. 
Ventilation rates were determined by tracer gas decay. Pure carbon dioxide $\left(\mathrm{CO}_{2}\right)$ from a cylinder was injected in front of an air inlet to mix the gas in a classroom in the early evening. The initial target $\mathrm{CO}_{2}$ concentration was $\sim 3,000 \mathrm{ppm}$. Concentrations in indoor and outdoor air were measured on a six-minute cycle with the calibrated $\mathrm{CO}_{2}$ monitors installed in the classroom. The ventilation rate in air changes per hour $\left(\mathrm{h}^{-1}\right)$ was calculated as the slope of the least squares linear regression of the natural $\log$ of indoor minus outdoor $\mathrm{CO}_{2}$ concentrations versus time. Data within the linear range were retained in the analysis.

Samples for VOCs and aldehydes were simultaneously collected inside and outdoors over an approximate one-hour period using pump systems set to operate at $\sim 50 \mathrm{~cm}^{3} \min ^{-1}$ and $\sim 1 \mathrm{~L} \mathrm{~min}^{-1}$ for VOCs and aldehydes, respectively.

\section{Data Analysis}

Emission rates (ERs) of the target compounds in mass per time $\left(\mathrm{mg} \mathrm{h}^{-1}\right)$ were calculated for the chamber study and derived for the classrooms assuming the chamber and the classrooms were ideal continuously-stirred tank reactors (CSTRs) operating at near steady-state conditions (ASTM, 1997). Losses of compounds due to factors other than ventilation (e.g., as the result of sink effects) were ignored; consequently, the calculated values were net rates. The steady-state form of the mass-balance model for CSTRs was used:

$$
E R=Q\left(C-C_{0}\right)
$$

where $\mathrm{Q}$ is the chamber inlet gas flow rate $\left(\mathrm{m}^{3} \mathrm{~h}^{-1}\right)$ or the $\mathrm{flow}$ rate of outside air $\left(\mathrm{m}^{3} \mathrm{~h}^{-1}\right)$ into the classrooms; $\mathrm{C}$ is the air concentration of the compound in the chamber or classroom $\left(\mu \mathrm{g} \mathrm{m}^{-3}\right)$; and $\mathrm{C}_{0}$ is the chamber background concentration or the outdoor air concentration $\left(\mu \mathrm{g} \mathrm{m}^{-3}\right)$.

Area-specific emission rates or emission factors (EFs) in mass per area-time $\left(\mu \mathrm{g} \mathrm{m}^{-2} \mathrm{~h}^{-1}\right)$ were calculated as:

$$
E F=\frac{Q\left(C-C_{O}\right)}{A}
$$

where A is the material surface area $\left(\mathrm{m}^{2}\right)$ for the chamber study and the floor area for the classroom study.

\section{Laboratory Study Results and Selection of Materials}


The alternate floor coverings, tackable wall panels and acoustic ceiling panels for the sourcemodified classrooms primarily were selected to have lower emissions of both toxic compounds of concern and odorous compounds than the standard materials typically used by the RC manufacturer. Attainment of reductions in the expected classroom concentrations of formaldehyde was a high priority in this process as formaldehyde is a potent sensory irritant and is considered a probable human carcinogen. Other selection criteria for the alternate materials included performance parameters (e.g., durability, maintenance requirements, and sound properties), appearance, cost, and acceptance by the school districts and the $\mathrm{RC}$ manufacturer. The project task covered the incremental material and labor costs associated with upgrading to the alternate materials. Additionally, the student desks in all classrooms were specified to have fully encapsulated tops to eliminate these furnishings as a strong VOC source.

SD A routinely installs an upgraded carpet in their schools and specified this carpet for use in both study classrooms. It is a Nylon-6,6 fiber broadloom carpet bonded to the plywood subfloor with a solvent-free full-spread adhesive. Approximately 12 gallons (45 L) of adhesive were used per classroom. A Nylon-6,6 fiber carpet with an olefin, chlorine free hardback was selected for use in the SD B modified classroom (SDB-A). This was intended to be installed using a dry adhesive mesh system. The mesh, however, did not bond properly to the plywood, and the carpet was installed with a solvent-free full-spread adhesive. In standard classroom SDB-B, an intermediate grade, Nylon-6 fiber broadloom carpet was installed, also with a solvent-free fullspread adhesive.

The same commercial grade, sheet vinyl floor covering used in all classrooms. However, the area of sheet vinyl floor covering was larger in the SD A classrooms than in the SD B classrooms.

The RC manufacturer follows standard industry practice and finishes the four walls of their classrooms with vinyl-covered fiberboard tackable wall panels. The alternate material selected for the modified classrooms was the same fiberboard panel covered with Teflon-coated vinyl. This coated vinyl material is primarily intended for use on surfaces in need of frequent cleaning, and may serve as a diffusion barrier to VOC emissions. 
The manufacturer finishes the grid ceilings of their classrooms using a fiberglass panel with a vinyl coating on its exposed surface. A mineral fiber ceiling panel with no detectable emissions of formaldehyde was selected as the alternate material for the two modified classrooms.

The only other interior finish material with a significant surface area was the built-in cabinetry. This cabinetry and the associated countertops were high quality units constructed with surfaces of the composite wood components encapsulated with laminate. This surface treatment substantially reduces the emissions of formaldehyde (Kelly et al., 1999). As our specifications for cabinetry were met and no lower emitting materials at reasonable cost were available, the cabinetry components were not tested for emissions of VOCs.

The standard and alternate materials selected and used to finish the interiors of the four classrooms are listed in Table 1 along with their exposed surface areas.

Emission factors (EFs) for chemicals of concern and odorous compounds emitted by the eight standard and alternate materials are given in Table 2. The compounds in this and subsequent tables are listed by chemical class (i.e., alcohols and glycol ethers, ketones, aldehydes, esters, terpene hydrocarbons and terpenols, aromatic hydrocarbons, chlorinated hydrocarbons, and nitrogen-containing compounds) and then in order of decreasing vapor pressure or volatility within each class. Lower LOQs for the EFs were approximately 3 $\mu \mathrm{g} \mathrm{m}^{-2} \mathrm{~h}^{-1}$ for formaldehyde and acetaldehyde and $1.5 \mu \mathrm{g} \mathrm{m}^{-2} \mathrm{~h}^{-1}$ for the other compounds. Values below these limits were not reported. In total, there were five odorous compounds ( $\alpha$-terpineol, hexanal, nonanal, decanal, and 4-phenylcyclohexene) and 11 toxic compounds of concern emitted by the eight materials. The specification of the carpet used in classroom SDB-B was changed subsequent to completion of the chamber study. Thus, the EFs for the Nylon-6 fiber carpet that was originally tested as an alternate were used as proxies for the installed material's EFs. However, the formaldehyde EF was excluded since this compound likely derived from the plywood used as the substrate for the test assembly.

For each material in the chamber study, the calculated VOC EFs were multiplied by the projected surface area of the material exposed in a classroom to predict the ERs attributable to the material. Then for each compound, the ERs from the various materials in a classroom were summed (Table 3). The predicted formaldehyde ERs were almost entirely attributable to the standard ceiling panel. 1,2,4-Trimethylbenzene, 1-methyl-2-pyrrolidinone, and di(ethylene 
glycol)butyl ether were almost entirely attributable to the standard wall panel. The alternate wall panel was predicted to virtually eliminate these compounds and measurably reduce the emissions of vinyl acetate. A tradeoff associated with using the alternate wall panel was the emergence of predicted toluene emissions in the modified classrooms. Carpets were the source of the caprolactam emissions in the SD B classrooms, with the Nylon- 6 carpet being the predominant source.

\section{Classroom Study Results}

\section{Ventilation Rates}

The code minimum ventilation rate for school classrooms is $15 \mathrm{cfm}\left(7 \mathrm{~L} \mathrm{~s}^{-1}\right.$ or $\left.26 \mathrm{~m}^{3} \mathrm{~h}^{-1}\right)$ per occupant (ASHRAE, 1989). The numbers of occupants were the obtained classroom enrollments, approximately 30 in SD A and 20 in SD B, plus one teacher. Thus, the design ventilation rates were $465 \mathrm{cfm}$ or $790 \mathrm{~m}^{3} \mathrm{~h}^{-1}$ for SD A and $315 \mathrm{cfm}$ or $535 \mathrm{~m}^{3} \mathrm{~h}^{-1}$ for SD B.

The ventilation rates measured by $\mathrm{CO}_{2}$ tracer gas decay in each of the classrooms for the preoccupancy, fall and spring sampling events are presented in Table 4. Calculated airflow rates are also shown. As previously noted, the standard HPAC systems used for the pre-occupancy measurements were not adjusted until later, and the fall and spring measurements were made with the IDEC systems. The calculated airflow rates were lower during the 27 week sampling event when the IDEC systems were predominantly in the heating mode. The airflow rates were higher than, or approximately equivalent to, the code-minimum ventilation requirements except at 27 weeks in classrooms SDA-A (39\% low) and SDB-B (12\% low).

\section{VOC Emission Rates}

The emission rates (ERs) of 28 VOCs, including formaldehyde and acetaldehyde, derived for the four classrooms immediately prior to first occupancy are presented in Table 5. Lower LOQs for indoor minus outdoor (i.e., adjusted indoor) concentrations were used to estimate lower LOQs for the ERs. The derived ERs of these compounds in the four classrooms eight and 27 weeks after first occupancy are shown in Tables 6 and 7, respectively. Decreases in ERs of selected VOCs with time after installation are illustrated in Figures 1 and 2 for classrooms SDA-B and SDB-B, respectively. For most of these compounds, there was a substantial drop in ERs between the time of installation and eight weeks after first occupancy, when many of the values were 
below LOQs. ERs of VOCs generally decreased between eight and 27 weeks; however, some of these changes were difficult to evaluate because the values were below their LOQs. In the final period, the formaldehyde and acetaldehyde ERs for classroom SDB-B were low but still quantifiable due to the corresponding low ventilation rate.

The derived ERs of formaldehyde in classroom SDB-A are notable. Initially, this classroom had the lowest formaldehyde ER of $2.4 \mathrm{mg} \mathrm{h}^{-1}$. At eight weeks, the formaldehyde ER increased more than ten-fold to $27 \mathrm{mg} \mathrm{h}^{-1}$. In the subsequent final sampling event, the formaldehyde ER was below the initial value and consistent with the values derived for the other classrooms. We were unsuccessful in our attempt to identify the transient source of the elevated fall ER. An inspection of the classroom shortly after the fall event revealed the presence of teaching aids. The date of introduction was determined to be prior to the eight-week sampling event. The teaching aids were personal pegboards constructed of hardboard with one exposed surface and personal dry-erase marking boards constructed of particleboard with one exposed surface. Both hardboard and particleboard have been identified as sources of formaldehyde (Kelly et al., 1999; Hodgson et al., 2002). Emissions of formaldehyde from specimens of these products collected from the classroom were measured in small-scale chambers at $96 \mathrm{~h}$ without conditioning. The

measured EFs for pegboards and marking boards were 86 and $570 \mu \mathrm{g} \mathrm{m}^{-2} \mathrm{~h}^{-1}$, respectively. Based on the sizes and numbers of teaching aids in the classroom, we predicted they could contribute $0.66 \mathrm{mg} \mathrm{h}^{-1}$ to the total derived formaldehyde ER, or only about 2.5 percent of the total. Thus, these materials were unlikely to be the source of the elevated formaldehyde ER. Another potential, but unmeasured, source of formaldehyde observed in the classroom at the time of ER sampling in the fall was a collection of painted paper mache art projects.

\section{Classroom VOC Concentrations}

Concentrations of VOCs measured in the classrooms when they were operating with the IDEC systems during the fall semester provide the best available measures of concentrations when the classrooms were new and operating with near code-minimum ventilation rates. We must note, however, the IDEC systems were not continuously operated by the teachers during some of the individual classroom/week sampling events, especially in the fall 2001 cooling season. Thus, the average ventilation rates during some of the measurement periods may have been below the minimum code requirements used to predict concentrations. The average adjusted indoor 
concentrations and concentration ranges of $15 \mathrm{VOCs}$, which were quantified in the chamber study, are presented by classroom in Table 8 . One of the compounds from the chamber study, di(ethylene glycol)butyl ether, was not detected in any of the classroom samples. Among the four classrooms, week-to-week variability as shown by the concentration ranges was generally lowest for classroom SDA-A. This was presumably the result of relatively consistent operation of the IDEC system in this classroom. Only formaldehyde had average adjusted indoor concentrations in excess of 5 parts-per-billion (ppb). Among the other compounds, only phenol, acetaldehyde, hexanal, nonanal, and caprolactam had average concentrations in excess of $1 \mathrm{ppb}$.

\section{Discussion}

Comparisons of adjusted indoor VOC concentrations and derived classroom ERs with their corresponding predicted values are indicators of how well VOC sources in classrooms can be estimated based on data generated by the small-scale laboratory studies. Due to the uncertainties involved in this process, the boundary for acceptable agreement has been defined as up to a factor of two divergence between actual and predicted values. The derived classroom ERs, which were determined immediately prior to occupancy and eight weeks after first occupancy for the 15 VOCs quantified in the chamber study, were compared to the predicted ERs of these VOCs. These comparisons are shown for school districts A and B in Tables 9 and 10, respectively. Compounds for which the derived ERs in either the pre-occupancy or the eightweek sampling event agreed within a factor of two of the predicted rates in two or more classrooms were phenol, formaldehyde, acetaldehyde, hexanal, toluene, and caprolactam. The primary sources of these compounds appear in Table 2. The un-coated, vinyl-covered tackable wall panel used in the standard classrooms was predicted to be a relatively large source of vinyl acetate, 1,2,4-trimethylbenzene and 1-methyl-2-pyrrolidinone. The Teflon-coated, vinyl-covered wall panel used in the modified classrooms also was predicted to be a large source of vinyl acetate. From the comparisons of derived and predicted ERs, it is apparent that the wall panels installed in the classrooms were substantially lower sources of these compounds than forecasted by the chamber study. Possible reasons are rapid decay in the emissions of these compounds from the panels and/or real differences between the tested and installed materials.

The average adjusted indoor concentrations of the 15 VOCs measured in the classrooms when they were operating with the IDEC systems during the fall semester are compared in Table 
11 to concentrations predicted by dividing the summed VOC ERs by their corresponding design ventilation rates. For more than one-third of the individual comparisons for which there were measurable classroom concentrations, 16 of 42 possible comparisons, the average measured concentrations were within a factor of two of the predicted concentrations.

The adjusted indoor concentrations measured during the fall semester when the classrooms were operating with the IDEC system at near code-minimum ventilation rates comprise the most useful data to evaluate the effectiveness of material selection for reducing potential VOC exposures in classrooms. Thus, adjusted indoor concentrations measured in modified and standard classrooms on weeks two, four, six and eight at each school district were paired by week creating eight pairs of measurements for the combined school districts. The hypothesis which stated there was no significant difference in mean concentrations between modified and standard classrooms when both were operating with the IDEC systems was tested with a paired Student's $t$ test (two-tailed test, seven degrees of freedom, $\mathrm{P}=0.05$ ). The results for the ten VOCs with sufficient numbers of data points above the LOQs are shown in Table 12. For caprolactam, the test was run with only the four pairs of measurements from SD B since there was no source of caprolactam in either classroom at SD A. Statistically significant differences in mean adjusted indoor VOC concentrations between modified and standard classrooms were observed for phenol, hexanal, nonanal, 1-methyl-2-pyrrolidinone, and caprolactam. In each case, the concentrations were lowest in the modified classrooms. With the exception of caprolactam, the mean concentration differences between modified and standard classrooms were less than 1 ppb.

It is of interest to compare VOC emissions in the classrooms with VOC emissions in other new buildings. A recent study measured VOC concentrations and ventilation rates in new HUDcode manufactured houses and site-built houses and found the same predominant compounds at similar concentrations in both house types (Hodgson et al., 2000). The houses were unoccupied and one to two months old when they were first sampled. The methodologies were similar to those employed in the classroom study. In Table 13, the ranges of derived VOC EFs in the four classrooms eight weeks after first occupancy are compared to the geometric mean EFs and ranges for the four manufactured houses in that study. Also shown in Table 13 are derived VOC EFs calculated from data generated by a detailed study of VOC sources in a single manufactured house (Hodgson et al., 2002). These comparisons were made for 14 compounds quantified in the 
classrooms and in one or both of the house studies. The classroom EFs of 2-butanone, hexanal, heptanal, 2-octenal, $\alpha$-pinene, and d-limonene were below the values derived for the houses, while toluene EFs were higher in the classrooms. Formaldehyde EFs, excluding the uncharacteristically high value in classroom SDB-A, were similar in the two building types.

There are several differences between the interior construction of the classrooms and houses, which suggest that emissions of some VOCs should be lower in the classrooms than in houses. In the manufactured houses, the cabinetry, which had large areas of bare composite wood surfaces, was shown to be a substantial source of formaldehyde, as well as a source of other aldehydes and terpene hydrocarbons such as $\alpha$-pinene (Hodgson et al., 2002). Substantially less cabinetry was used in the classrooms, and this cabinetry was constructed with all surfaces including the undersides of countertops encapsulated with laminate. Another difference was the carpet system used in the two types of buildings. In the houses, the carpet was installed over a carpet cushion using tack strips. This installation method has little effect on the emissions of higher molecular weight aldehydes and terpene hydrocarbons from the plywood subfloor (Hodgson et al., 2002). In the classrooms, the installation of the carpet directly over the plywood subfloor with full-spread adhesive may have contributed to the low emissions of formaldehyde and other VOCs often associated with plywood.

\section{Conclusions}

The study produced encouraging results regarding the emissions of toxic and odorous volatile organic compounds (VOCs) of potential concern from the materials used to construct the interiors of these relocatable classrooms (RCs). The classroom interiors generally were shown to be low sources of specific VOCs including odorous aldehydes. Thus, concentrations as the result of material emissions were anticipated to be relatively low, which was also influenced by the substantially higher ventilation rates required in classrooms than in other settings, e.g., houses, due to higher occupant densities. In fact, when the classrooms were operating during the fall 2001 cooling season with the advanced IDEC systems, only the average adjusted indoor concentrations of formaldehyde exceeded $5 \mathrm{ppb}$, while the majority of the target compounds had average concentrations less than $1 \mathrm{ppb}$.

Emission rates (ERs) of most VOCs were shown to decrease substantially with time following installation of the classrooms. As a consequence of these decreases, the derived ERs 
of many compounds were below lower limits of quantitation at eight and 27 weeks after first occupancy.

In roughly one third of the compared cases, VOC ERs and concentrations in the classrooms were predicted with reasonable accuracy, i.e., within a factor of two, based on the results of the laboratory study of material emissions. Some of the largest discrepancies occurred because the standard and alternate vinyl-covered wall panels installed in the classrooms were lower sources of VOCs than projected from the laboratory study. An exception was formaldehyde in one classroom, whose ERs and concentrations were elevated over the predicted values. Although the source was not identified, the transient elevation likely was not due to the interior finish materials.

Differences in mean VOC concentrations over the fall 2001 cooling season between modified and standard classrooms were small, i.e., typically less than $1 \mathrm{ppb}$ on average, when the classrooms were operated with the IDEC systems. Nevertheless, for five compounds, these differences were statistically significant. Lower concentrations of phenol in modified classrooms likely were due to the use of Teflon-coated vinyl-covered wall panels and/or the mineral fiber ceiling panels. Lower concentrations of 1-methyl-2-pyrrolidone likely were due to the alternate wall panels. The use of carpets without Nylon- 6 fibers resulted in low to non-detectable concentrations of caprolactam.

In general, the emissions of VOCs from the standard materials used by the manufacturer were sufficiently low to achieve acceptable air quality assuming that code-minimum ventilation rates are maintained. Under these conditions, the small magnitude of the beneficial effects attributable to the use of alternate interior finish materials suggests that it is not imperative to use such materials. However, it is probable that there will be periods in many classrooms during which ventilation rates are below code requirements due to teacher preference (e.g., as observed in this study), improper adjustment, or poor maintenance. Thus, it is important that low VOCimpact materials are used to accommodate reduced ventilation rate conditions. The results of this study demonstrated that the process of laboratory-based material testing combined with modeling of expected air pollutant concentrations and field validation was sufficiently accurate to inform the material selection process with the goal of reducing potential occupant exposures to toxic indoor air pollutants. 


\section{Acknowledgements}

This study was sponsored by the California Energy Commission through the Public Interest Energy Research program as Element 6.2.2 of the Lawrence Berkeley National Laboratory High Performance Commercial Buildings Systems research contract number 400-99-012. The study was additionally supported by the U.S. Department of Energy under Lawrence Berkeley National Laboratory contract number DE-AC03-76SF00098. The authors thank the participating staff from American Modular Systems, school district facilities offices, and school administration staff, teachers, and students. The authors also gratefully acknowledge the assistance of many LBNL staff members including Dennis DiBartolomeo, Tosh Hotchi, Seung-Min Lee, Marion Russell, and Doug Sullivan.

\section{References}

ASHRAE (1989) Ventilation for acceptable indoor air quality, Atlanta, GA, American Society of Heating, Refrigerating, and Air Conditioning Engineers, Inc. (ASHRAE Standard 621989).

ASTM (1997) Standard Guide for Small-Scale Environmental Chamber Determinations of Organic Emissions from Indoor Materials/Products, Philadelphia, PA, American Society for Testing and Materials (ASTM Standard D 5116-97).

Hodgson, A.T., Rudd, A.F., Beal, D. and Chandra, S. (2000) Volatile organic compounds concentrations and emission rates in new manufactured and site-built houses, Indoor Air,10, 178-192.

Hodgson, A.T, Fisk, W.J, Shendell, D.G. and Apte, M.G. (2001) Predicted concentrations in new relocatable classrooms of volatile organic compounds emitted from standard and alternate interior finish materials, Report No. LBNL-48490 Lawrence Berkeley National Laboratory, Berkeley, CA, July 2001.

Hodgson, A.T., Beal, D. and McIlvaine, J.E.R. (2002) Sources of formaldehyde, other aldehydes and terpenes in a new manufactured house, Indoor Air, 12, 235-242.

Kelly, T.J., Smith, D.L. and Satola, J. (1999) Emission rates of formaldehyde from materials and consumer products found in California Homes, Environmental Science and Technology, 33, 81-88. 
Shendell, D.G., DiBartolomeo, D., Fisk, W.J., Hodgson, A.T., Hotchi, T., Lee, S-M., Sullivan, D.P., Apte, M.G. and Rainer, L.I. (2002a) Final Methodology for a Field Study of Indoor Environmental Quality and Energy Efficiency in New Relocatable Classrooms in Northern California, Report No. LBNL-51101, Lawrence Berkeley National Laboratory, Berkeley, CA, August 2002.

Shendell, D.G., Hodgson, A.T., Lee, S-M., Apte, M.G., Sullivan, D.P., Hotchi, T. and Fisk, W.J. (2002b) VOCs in New Relocatable Classrooms: Assessment of School-Day Exposures Comparing Interior Finish Materials and HVAC Systems. Poster presented at the joint annual meeting of the International Society of Exposure Analysis $\left(12^{\text {th }}\right)$ and the International Society of Environmental Epidemiology $\left(14^{\text {th }}\right)$, Vancouver, B.C., Canada, August 11-15, 2002. Abstract published in Epidemiology, 13 (4), S143. 
Table 1. Projected surface areas of standard and alternate interior finish materials installed in four classrooms

\begin{tabular}{|c|c|c|c|c|c|}
\hline \multirow[b]{3}{*}{ Material Description } & \multirow{3}{*}{$\begin{array}{l}\text { Lab. } \\
\text { Code }\end{array}$} & \multicolumn{4}{|c|}{ Surface Area $\left(\mathrm{m}^{2}\right)$} \\
\hline & & \multicolumn{2}{|c|}{ Sch. Dist. A Classrm. } & \multicolumn{2}{|c|}{ Sch. Dist. B Classrm. } \\
\hline & & SDA-A & SDA-B & SDB-A & SDB-B \\
\hline \multicolumn{6}{|l|}{ Floor } \\
\hline $\begin{array}{l}\text { Nylon- } 6,6 \text { broadloom } \\
\text { carpet }^{\mathbf{a}, \mathbf{b}}\end{array}$ & BLC2 & 72.0 & 72.0 & & \\
\hline Nylon-6 broadloom carpet ${ }^{\mathbf{a}}$ & $\mathrm{BLC}^{\mathrm{c}}$ & & & & 81.5 \\
\hline $\begin{array}{l}\text { Nylon-6,6 olefin hardback } \\
\text { carpet }^{\mathbf{a}, \mathbf{b}}\end{array}$ & $\mathrm{HBC}$ & & & 81.5 & \\
\hline Sheet vinyl flooring & SVF & 12.8 & 12.8 & 3.3 & 3.3 \\
\hline \multicolumn{6}{|l|}{ Walls } \\
\hline $\begin{array}{l}\text { Vinyl-covered fiberboard } \\
\text { wall panels }\end{array}$ & VWP1 & & 92.0 & & 92.0 \\
\hline $\begin{array}{l}\text { Teflon-coated vinyl-covered } \\
\text { fiberboard wall panels }{ }^{\mathbf{b}}\end{array}$ & VWP2 & 92.0 & & 92.0 & \\
\hline \multicolumn{6}{|l|}{ Ceiling } \\
\hline Fiberglass ceiling panels & FCP & & 84.8 & & 84.8 \\
\hline Mineral fiber ceiling panels ${ }^{\mathbf{b}}$ & MCP2 & 84.8 & & 84.8 & \\
\hline
\end{tabular}

a. Bonded to plywood subfloor with solvent-free, full-spread adhesive.

b. Alternate interior finish material for source-modified classrooms.

c. Installed carpet had similar face fibers as carpet designated BLC3 in laboratory study. 
Table 2. Laboratory measured VOC emission factors for standard and alternate interior finish materials installed in four classrooms

\begin{tabular}{|c|c|c|c|c|c|c|c|c|}
\hline \multirow[b]{3}{*}{ Compound } & \multicolumn{8}{|c|}{ Emission Factor $\left(\mu \mathrm{g} \mathrm{m}^{-2} \mathrm{~h}^{-1}\right)$} \\
\hline & & \multicolumn{2}{|c|}{ Floor Coverings } & \multirow[b]{2}{*}{ SVF } & \multicolumn{2}{|c|}{ Wall Panels } & \multicolumn{2}{|c|}{ Ceiling Panels } \\
\hline & $\mathrm{BLC}^{\mathrm{a}}$ & $\mathrm{BLC}^{\mathrm{b}}$ & $\mathrm{HBC}$ & & VWP1 & VWP2 & FCP & MCP2 \\
\hline Phenol & & & & 240 & 53 & 6.1 & 18.1 & \\
\hline DEGBE $^{\mathfrak{c}}$ & 6.0 & & & & 50 & & & \\
\hline 2-Butanone & 3.4 & & & & & & & \\
\hline Formaldehyde & & & 4.0 & & & & 32 & \\
\hline Acetaldehyde & 24 & 13.0 & & 12.8 & 46 & 23 & & \\
\hline Hexanal & 41 & 46 & & & & & & \\
\hline Nonanal & & 6.6 & & & & & & 2.6 \\
\hline Decanal & 1.7 & 2.7 & & & 7.5 & 2.0 & & \\
\hline Vinyl acetate & & & & & 840 & 290 & & \\
\hline$\alpha$-Terpineol & 2.6 & & & & & & & \\
\hline Toluene & & & & & & 20 & & \\
\hline $1,2,4-\mathrm{TMB}^{\mathrm{c}}$ & & & & 26 & 100 & & & \\
\hline Naphthalene & 3.4 & & & & & & & \\
\hline 4-PCH ${ }^{\mathrm{c}}$ & & 2.6 & & & & & & \\
\hline $\mathrm{NMP}^{\mathrm{c}}$ & & & & & 158 & & & \\
\hline Caprolactam & & 126 & 8.5 & & & & & \\
\hline
\end{tabular}

a. Material identification codes used in laboratory study are defined in Table 1 .

b. EFs for Nylon- 6 carpet that was originally tested as alternate were used as proxies for installed material's EFs (see text).

c. $\mathrm{DEGBE}=\mathrm{Di}$ (ethylene glycol)butyl ether; 1,2,4-TMB = 1,2,4-trimethylbenzene; 4-PCH = 4-phenylcyclohexene; NMP = 1-methyl-2-pyrrolidinone 
Table 3. Predicted emission rates of toxic and odorous VOCs in four classrooms

\begin{tabular}{|c|c|c|c|c|}
\hline \multirow[b]{3}{*}{ Compound } & \multicolumn{4}{|c|}{ Predicted Emission Rate $\left(\mathrm{mg} \mathrm{h}^{-1}\right)$} \\
\hline & \multicolumn{2}{|c|}{$\underline{\text { Sch. Dist. A Classrm. }}$} & \multicolumn{2}{|c|}{ Sch. Dist. B Classrm. } \\
\hline & SDA-A & SDA-B & SDB-A & SDB-B \\
\hline Phenol & 3.6 & 9.5 & 1.35 & 7.2 \\
\hline DEGBE* & 0.43 & 5.0 & -- & 4.6 \\
\hline 2-Butanone & 0.24 & 0.24 & -- & -- \\
\hline Formaldehyde & -- & 2.7 & 0.33 & 2.7 \\
\hline Acetaldehyde & 2.3 & 4.4 & 2.1 & 5.4 \\
\hline Hexanal & 3.0 & 3.0 & -- & 3.8 \\
\hline Nonanal & 0.22 & -- & 0.22 & 0.54 \\
\hline Decanal & 0.31 & 0.81 & 0.18 & 0.91 \\
\hline Vinyl acetate & 27 & 77 & 27 & 77 \\
\hline$\alpha$-Terpineol & 0.19 & 0.19 & -- & -- \\
\hline Toluene & 1.87 & -- & 1.87 & -- \\
\hline $1,2,4-\mathrm{TMB}^{*}$ & 0.34 & 9.5 & 0.09 & 9.3 \\
\hline Naphthalene & 0.24 & 0.24 & -- & -- \\
\hline 4-PCH* & -- & -- & -- & 0.21 \\
\hline NMP* & -- & 14.5 & -- & 14.5 \\
\hline Caprolactam & -- & -- & 0.69 & 10.3 \\
\hline
\end{tabular}

*Compound abbreviations defined in Table 2. 
Table 4. Ventilation rates measured by $\mathrm{CO}_{2}$ tracer gas decay and calculated outdoor air (OA) flow rates in four classrooms for the pre-occupancy, fall (eight-week) and spring (27-week) sampling events

\begin{tabular}{|c|c|c|c|c|}
\hline \multirow[b]{2}{*}{ Ventilation Parameter } & \multicolumn{2}{|c|}{$\underline{\text { Sch. Dist. A Classrm. }}$} & \multicolumn{2}{|c|}{$\underline{\text { Sch. Dist. B Classrm. }}$} \\
\hline & SDA-A & SDA-B & SDB-A & SDB-B \\
\hline \multicolumn{5}{|l|}{ Pre-occupancy $^{\mathrm{a}}$} \\
\hline Ventilation rate $\left(\mathrm{h}^{-1}\right)$ & 8.2 & 4.5 & 1.49 & 1.74 \\
\hline OA Flow rate $\left(\mathrm{m}^{3} \mathrm{~h}^{-1}\right)$ & 1,800 & 990 & 330 & 380 \\
\hline \multicolumn{5}{|l|}{ Fall semester ${ }^{b}$} \\
\hline Ventilation rate $\left(\mathrm{h}^{-1}\right)$ & 3.5 & 4.2 & 3.4 & 2.8 \\
\hline OA Flow rate $\left(\mathrm{m}^{3} \mathrm{~h}^{-1}\right)$ & 780 & 920 & 740 & 610 \\
\hline \multicolumn{5}{|l|}{ Spring semester ${ }^{b}$} \\
\hline Ventilation rate $\left(\mathrm{h}^{-1}\right)$ & 2.2 & 3.5 & 2.4 & 2.1 \\
\hline OA Flow rate $\left(\mathrm{m}^{3} \mathrm{~h}^{-1}\right)$ & $480^{c}$ & 760 & 530 & $470^{\mathrm{c}}$ \\
\hline
\end{tabular}

a. Standard HPAC system prior to final adjustment of airflow rates.

b. IDEC system.

c. More than $10 \%$ below design ventilation rate. 
Table 5. Derived emission rates of VOCs in four classrooms prior to first occupancy

\begin{tabular}{|c|c|c|c|c|}
\hline \multirow[b]{3}{*}{ Compound } & \multicolumn{4}{|c|}{ Derived Emission Rate $\left(\mathrm{mg} \mathrm{h}^{-1}\right)$} \\
\hline & \multicolumn{2}{|c|}{ Sch. Dist. A Classrm. } & \multicolumn{2}{|c|}{ Sch. Dist. B Classrm. } \\
\hline & SDA-A & SDA-B & SDB-A & SDB-B \\
\hline Phenol & 4.8 & 6.7 & 0.34 & 1.23 \\
\hline 2-Propanone & $<26$ & 17.4 & 15.2 & 27 \\
\hline 2-Butanone & 2.7 & 5.0 & 0.87 & 1.18 \\
\hline Formaldehyde & 7.1 & 9.9 & 2.4 & 3.8 \\
\hline Acetaldehyde & $<2.7$ & 4.0 & 4.8 & 2.0 \\
\hline Pentanal & 1.44 & 1.14 & 1.41 & 1.73 \\
\hline Hexanal & 6.0 & 5.6 & 2.7 & 7.5 \\
\hline Heptanal & 2.7 & 0.78 & 0.69 & 1.53 \\
\hline Octanal & $<1.46$ & $<0.80$ & 0.87 & 1.21 \\
\hline 2-Octenal & $<0.56$ & 0.75 & $<0.10$ & 0.40 \\
\hline Nonanal & 13.5 & 4.3 & 2.7 & 14.4 \\
\hline Decanal & $<4.1$ & $<2.3$ & 1.43 & 1.35 \\
\hline Vinyl acetate & 3.5 & 7.4 & 8.0 & 0.74 \\
\hline Ethyl acetate & $<5.8$ & 9.4 & 7.6 & 18.2 \\
\hline$\alpha$-Pinene & 5.8 & 8.5 & 3.5 & 6.6 \\
\hline d-Limonene & 0.94 & 0.89 & 0.42 & 1.21 \\
\hline$\alpha$-Terpineol & $<0.09$ & $<0.05$ & $<0.02$ & 0.27 \\
\hline Toluene & 5.2 & 2.6 & 3.5 & 1.15 \\
\hline Styrene & $<0.07$ & 0.11 & 0.21 & 0.26 \\
\hline $1,2,4-\mathrm{TMB}^{*}$ & 1.12 & 1.31 & 0.92 & 1.13 \\
\hline Naphthalene & $<0.05$ & 0.82 & 0.52 & 0.07 \\
\hline 4-PCH* & $<0.16$ & $<0.09$ & $<0.03$ & 0.57 \\
\hline Dichloromethane & $<17.3$ & $<9.5$ & $<3.1$ & $<3.7$ \\
\hline Carbon tetrachloride & $<0.13$ & 0.24 & $<0.02$ & 0.07 \\
\hline Trichloroethene & 1.68 & 2.2 & $<0.01$ & $<0.02$ \\
\hline Tetrachloroethene & $<0.09$ & $<0.05$ & $<0.02$ & 0.07 \\
\hline NMP* & $<0.18$ & 3.4 & $<0.03$ & 1.83 \\
\hline Caprolactam & 3.5 & 4.5 & $<0.33$ & 5.3 \\
\hline
\end{tabular}

*Compound abbreviations defined in Table 2. 
Table 6. Derived emission rates of VOCs in four classrooms eight weeks after first occupancy

\begin{tabular}{|c|c|c|c|c|}
\hline \multirow[b]{3}{*}{ Compound } & \multicolumn{4}{|c|}{ Derived Emission Rate $\left(\mathrm{mg} \mathrm{h}^{-1}\right)$} \\
\hline & \multicolumn{2}{|c|}{ Sch. Dist. A Classrm. } & \multicolumn{2}{|c|}{ Sch. Dist. B Classrm. } \\
\hline & SDA-A & SDA-B & SDB-A & SDB-B \\
\hline Phenol & $<0.26$ & 0.30 & $<0.24$ & $<0.20$ \\
\hline 2-Propanone & $<11.4$ & $<13.5$ & $<10.9$ & $<9.0$ \\
\hline 2-Butanone & $<0.58$ & $<0.69$ & 0.67 & $<0.46$ \\
\hline Formaldehyde & 2.8 & 3.6 & 27 & $<1.98$ \\
\hline Acetaldehyde & $<1.17$ & 1.41 & 1.39 & $<0.92$ \\
\hline Pentanal & $<0.50$ & $<0.59$ & $<0.47$ & $<0.39$ \\
\hline Hexanal & $<2.7$ & $<3.2$ & $<2.5$ & $<2.1$ \\
\hline Heptanal & $<0.25$ & $<0.29$ & $<0.24$ & $<0.20$ \\
\hline Octanal & $<0.63$ & $<0.75$ & $<0.60$ & $<0.50$ \\
\hline 2-Octenal & $<0.24$ & $<0.29$ & $<0.23$ & $<0.19$ \\
\hline Nonanal & $<1.77$ & $<2.1$ & $<1.69$ & $<1.39$ \\
\hline Decanal & $<1.79$ & $<2.12$ & $<1.71$ & $<1.41$ \\
\hline Vinyl acetate & $<0.17$ & $<0.20$ & $<0.16$ & $<0.13$ \\
\hline Ethyl acetate & $<2.5$ & $<3.0$ & $<2.4$ & $<1.98$ \\
\hline$\alpha$-Pinene & 1.20 & 1.26 & 0.43 & 0.35 \\
\hline d-Limonene & 0.82 & 0.79 & 0.50 & 0.39 \\
\hline$\alpha$-Terpineol & $<0.04$ & $<0.05$ & $<0.04$ & $<0.03$ \\
\hline Toluene & 1.21 & 0.95 & 2.9 & 2.2 \\
\hline Styrene & 0.19 & 0.18 & 0.12 & 0.09 \\
\hline $1,2,4-\mathrm{TMB}^{*}$ & 0.40 & 0.33 & 0.79 & 0.60 \\
\hline Naphthalene & 0.10 & 0.21 & 0.18 & 0.14 \\
\hline 4-PCH* & $<0.07$ & $<0.08$ & $<0.07$ & $<0.06$ \\
\hline Dichloromethane & $<7.5$ & $<8.8$ & $<7.1$ & $<5.9$ \\
\hline Carbon tetrachloride & $<0.05$ & $<0.06$ & $<0.05$ & $<0.04$ \\
\hline Trichloroethene & 0.19 & $<0.04$ & $<0.03$ & $<0.02$ \\
\hline Tetrachloroethene & $<0.04$ & $<0.05$ & 0.13 & 0.11 \\
\hline NMP* & 0.10 & 0.34 & $<0.07$ & 0.12 \\
\hline Caprolactam & $<0.78$ & $<0.92$ & $<0.74$ & 1.91 \\
\hline
\end{tabular}

*Compound abbreviations defined in Table 2 . 
Table 7. Derived emission rates of VOCs in four classrooms 27 weeks after first occupancy

\begin{tabular}{|c|c|c|c|c|}
\hline \multirow[b]{3}{*}{ Compound } & \multicolumn{4}{|c|}{ Derived Emission Rate $\left(\mathrm{mg} \mathrm{h}^{-1}\right)$} \\
\hline & \multicolumn{2}{|c|}{$\underline{\text { Sch. Dist. A Classrm. }}$} & \multicolumn{2}{|c|}{ Sch. Dist. B Classrm. } \\
\hline & SDA-A & SDA-B & SDB-A & SDB-B \\
\hline Phenol & $<0.16$ & 0.69 & $<0.17$ & $<0.15$ \\
\hline 2-Propanone & $<7.1$ & $<11.2$ & $<7.7$ & $<6.8$ \\
\hline 2-Butanone & $<0.36$ & $<0.57$ & $<0.40$ & $<0.35$ \\
\hline Formaldehyde & $<1.56$ & $<2.5$ & 2.1 & 2.0 \\
\hline Acetaldehyde & $<0.73$ & $<1.15$ & $<0.80$ & 0.82 \\
\hline Pentanal & $<0.31$ & $<0.49$ & $<0.34$ & $<0.30$ \\
\hline Hexanal & $<1.65$ & $<2.6$ & $<1.81$ & $<1.60$ \\
\hline Heptanal & $<0.15$ & $<0.24$ & $<0.17$ & 0.21 \\
\hline Octanal & $<0.39$ & $<0.62$ & $<0.43$ & $<0.38$ \\
\hline 2-Octenal & $<0.15$ & $<0.24$ & $<0.16$ & $<0.14$ \\
\hline Nonanal & $<1.10$ & $<1.74$ & $<1.20$ & 1.65 \\
\hline Decanal & $<1.11$ & $<1.76$ & $<1.21$ & $<1.07$ \\
\hline Vinyl acetate & $<0.11$ & $<0.17$ & $<0.12$ & $<0.10$ \\
\hline Ethyl acetate & $<1.56$ & $<2.5$ & $<1.71$ & $<1.51$ \\
\hline$\alpha$-Pinene & $<0.22$ & 0.38 & $<0.24$ & $<0.21$ \\
\hline d-Limonene & 0.41 & 0.35 & 0.61 & $<0.21$ \\
\hline$\alpha$-Terpineol & $<0.02$ & $<0.04$ & $<0.03$ & $<0.02$ \\
\hline Toluene & $<0.29$ & 0.60 & $<0.32$ & 0.44 \\
\hline Styrene & $<0.02$ & $<0.03$ & $<0.02$ & 0.07 \\
\hline $1,2,4-\mathrm{TMB}^{*}$ & 0.10 & 0.27 & 0.08 & 0.14 \\
\hline Naphthalene & $<0.01$ & 0.15 & $<0.02$ & $<0.01$ \\
\hline 4-PCH* & $<0.04$ & $<0.07$ & $<0.05$ & $<0.04$ \\
\hline Dichloromethane & $<4.6$ & $<7.3$ & $<5.1$ & 9.8 \\
\hline Carbon tetrachloride & $<0.03$ & 0.07 & $<0.04$ & $<0.03$ \\
\hline Trichloroethene & $<0.02$ & $<0.03$ & $<0.02$ & $<0.02$ \\
\hline Tetrachloroethene & $<0.02$ & $<0.04$ & $<0.03$ & $<0.02$ \\
\hline NMP* & $<0.05$ & 0.24 & $<0.05$ & 0.14 \\
\hline Caprolactam & $<0.48$ & $<0.76$ & $<<0.53$ & 2.9 \\
\hline
\end{tabular}

*Compound abbreviations defined in Table 2. 
Table 8. Indoor minus outdoor concentrations of toxic and odorous VOCs (average and range) in four classrooms during fall cooling season with IDEC system operating

\begin{tabular}{|c|c|c|c|c|c|c|c|c|}
\hline \multirow[b]{3}{*}{ Compound } & \multicolumn{8}{|c|}{ Concentration $(\mathrm{ppb})$} \\
\hline & \multicolumn{2}{|c|}{$\begin{array}{l}\text { SDA-A } \\
(\mathrm{n}=4)\end{array}$} & \multicolumn{2}{|c|}{$\begin{array}{l}\text { SDA-B } \\
(n=4)\end{array}$} & \multicolumn{2}{|c|}{$\begin{array}{c}\text { SDB-A } \\
(\mathrm{n}=4)\end{array}$} & \multicolumn{2}{|c|}{$\begin{array}{l}\text { SDB-B } \\
(\mathrm{n}=5)\end{array}$} \\
\hline & Avg. & Range & Avg. & Range & Avg. & Range & Avg. & Range \\
\hline Phenol & 0.56 & $0.34-0.75$ & 1.62 & $0.80-2.5$ & 0.41 & $<0.08-0.98$ & 0.84 & $0.21-1.37$ \\
\hline 2-Butanone & $<0.26$ & $<0.26-0.28$ & $<0.26$ & $<0.26-0.36$ & $<0.26$ & $<0.26-0.36$ & $<0.26$ & $<0.26-0.39$ \\
\hline Formaldehyde & 4.2 & $3.0-4.7$ & 9.9 & $3.5-19.2$ & 12.2 & 8.4-17.4 & 6.1 & $2.8-10.6$ \\
\hline Acetaldehyde & 0.64 & $<0.42-1.30$ & 1.79 & $<0.42-4.8$ & 2.2 & $<0.42-5.2$ & 1.50 & $<0.42-3.0$ \\
\hline Hexanal & $<0.84$ & $<0.84-0.90$ & 1.62 & $<0.84-3.0$ & 1.96 & $1.33-3.0$ & 2.8 & $1.23-3.6$ \\
\hline Nonanal & 0.92 & $0.62-1.22$ & 1.41 & $0.66-2.1$ & 1.06 & $0.34-1.68$ & 2.3 & $0.98-3.7$ \\
\hline Decanal & $<0.36$ & $<0.36-0.54$ & 0.36 & $<0.36-0.54$ & $<0.36$ & $<0.36$ & 0.40 & $<0.36-0.95$ \\
\hline Vinyl acetate & $<0.06$ & $<0.06$ & 0.11 & $<0.06-0.20$ & 0.22 & $0.10-0.43$ & $<0.06$ & $<0.06$ \\
\hline$\alpha$-Terpineol & $<0.01$ & $<0.01$ & 0.02 & $<0.01-0.05$ & 0.04 & $0.03-0.06$ & 0.06 & $<0.01-0.12$ \\
\hline Toluene & 0.41 & $0.26-0.70$ & 0.42 & $0.25-0.62$ & 1.06 & $0.46-1.86$ & 0.52 & $0.27-0.98$ \\
\hline $1,2,4-\mathrm{TMB}^{*}$ & 0.08 & $0.06-0.10$ & 0.19 & $0.08-0.30$ & 0.16 & $0.07-0.26$ & 0.09 & $0.03-0.15$ \\
\hline Naphthalene & 0.04 & 0.040 .05 & 0.20 & $0.09-0.30$ & 0.07 & $0.04-0.14$ & 0.01 & $<0.01-0.04$ \\
\hline 4-PCH* & $<0.02$ & $<0.02$ & $<0.02$ & $<0.02$ & $<0.02$ & $<0.02$ & 0.09 & $<0.02-0.15$ \\
\hline NMP* & $<0.02$ & $<0.02$ & 0.34 & $0.16-0.53$ & 0.06 & $<0.2-0.12$ & 0.91 & $0.22-1.79$ \\
\hline Caprolactam & $<0.22$ & $<0.22$ & $<0.22$ & $<0.22$ & $<0.22$ & $<0.22-0.30$ & 4.8 & $2.3-6.5$ \\
\hline
\end{tabular}

*Compound abbreviations defined in Table 2. 
Table 9. Comparison of predicted and derived emission rates for School District A source-modified and standard classrooms. Derived values in bold text are within factor of two of predicted values.

\begin{tabular}{|c|c|c|c|c|c|c|}
\hline \multirow[b]{4}{*}{ Compound } & \multicolumn{6}{|c|}{ Emission Rate $\left(\mathrm{mg} \mathrm{h}^{-1}\right)$} \\
\hline & \multirow{2}{*}{\multicolumn{3}{|c|}{$\begin{array}{c}\text { Classroom SDA-A } \\
\text { Derived }\end{array}$}} & \multirow{2}{*}{\multicolumn{3}{|c|}{$\begin{array}{r}\text { Classroom SDA-B } \\
\text { Derived }\end{array}$}} \\
\hline & & & & & & \\
\hline & Predicted & Pre-occup. & 8-Weeks & Predicted & Pre-occup. & 8-Weeks \\
\hline Phenol & 3.6 & 4.8 & $<0.26$ & 9.4 & 6.7 & 0.30 \\
\hline 2-Butanone & 0.24 & 2.7 & $<0.58$ & 0.24 & 5.0 & $<0.69$ \\
\hline Formaldehyde & -- & 7.1 & 2.8 & 2.7 & 9.9 & 3.6 \\
\hline Acetaldehyde & 2.3 & $<2.7$ & $<1.17$ & 4.4 & 4.0 & 1.41 \\
\hline Hexanal & 3.0 & 6.0 & $<2.7$ & 3.0 & 5.6 & $<3.2$ \\
\hline Nonanal & 0.22 & 13.5 & $<1.77$ & -- & 4.3 & $<2.1$ \\
\hline Decanal & 0.31 & $<4.1$ & $<1.79$ & 0.81 & $<2.3$ & $<2.1$ \\
\hline Vinyl acetate & 27 & 3.5 & $<0.17$ & 77 & 7.4 & $<0.20$ \\
\hline a-Terpineol & 0.19 & $<0.09$ & $<0.04$ & 0.19 & $<0.05$ & $<0.05$ \\
\hline Toluene & 1.87 & 5.2 & 1.21 & -- & 2.6 & 0.95 \\
\hline $1,2,4-\mathrm{TMB}^{*}$ & 0.34 & 1.12 & 0.40 & 9.5 & 1.31 & 0.33 \\
\hline Naphthalene & 0.24 & $<0.05$ & 0.10 & 0.24 & 0.82 & 0.21 \\
\hline 4-PCH* & -- & $<0.16$ & $<0.07$ & -- & $<0.09$ & $<0.08$ \\
\hline NMP* & -- & $<0.18$ & 0.10 & 14.5 & 3.4 & 0.34 \\
\hline Caprolactam & -- & 3.5 & $<0.78$ & -- & 4.5 & $<0.92$ \\
\hline
\end{tabular}

*Compound abbreviations defined in Table 2. 
Table 10. Comparison of predicted and derived emission rates for School District B source-modified and standard classrooms. Derived values in bold text are within factor of two of predicted values.

\begin{tabular}{|c|c|c|c|c|c|c|}
\hline & \multicolumn{6}{|c|}{ Emission Rate $\left(\mathrm{mg} \mathrm{h}^{-1}\right)$} \\
\hline & \multirow{2}{*}{\multicolumn{3}{|c|}{$\begin{array}{c}\text { Classroom SDB-A } \\
\text { Derived }\end{array}$}} & \multirow{2}{*}{\multicolumn{3}{|c|}{ Classroom SDB-B }} \\
\hline & & & & & & \\
\hline & Predicted & Pre-occup. & 8-Weeks & Predicted & Pre-occup. & 8-Weeks \\
\hline Phenol & 1.35 & 0.34 & $<0.24$ & 7.2 & 1.23 & $<0.20$ \\
\hline 2-Butanone & -- & 0.87 & 0.67 & -- & 1.18 & $<0.46$ \\
\hline Formaldehyde & 0.33 & 2.4 & 27 & 2.7 & 3.8 & $<1.98$ \\
\hline Acetaldehyde & 2.1 & 4.8 & 1.39 & 5.4 & 2.0 & $<0.92$ \\
\hline Hexanal & -- & 2.7 & $<2.5$ & 3.8 & 7.5 & $<2.1$ \\
\hline Nonanal & 0.22 & 2.7 & $<1.69$ & 0.54 & 14.4 & $<1.39$ \\
\hline Decanal & 0.18 & 1.43 & $<1.71$ & 0.91 & 1.35 & $<1.41$ \\
\hline Vinyl acetate & 27 & 8.0 & $<0.16$ & 77 & 0.74 & $<0.13$ \\
\hline a-Terpineol & -- & $<0.02$ & $<0.04$ & -- & 0.27 & $<0.03$ \\
\hline Toluene & 1.87 & 3.5 & 2.9 & -- & 1.15 & 2.2 \\
\hline $1,2,4-\mathrm{TMB}^{*}$ & 0.09 & 0.92 & 0.79 & 9.3 & 1.13 & 0.60 \\
\hline Naphthalene & -- & 0.52 & 0.18 & -- & 0.07 & 0.14 \\
\hline 4-PCH* & -- & $<0.03$ & $<0.07$ & 0.21 & 0.57 & $<0.06$ \\
\hline NMP* & -- & $<0.03$ & $<0.07$ & 14.5 & 1.83 & 0.12 \\
\hline Caprolactam & 0.69 & $<0.33$ & $<0.74$ & 10.3 & 5.3 & 1.91 \\
\hline
\end{tabular}

*Compound abbreviations defined in Table 2. 
Table 11. Comparison of predicted and measured indoor minus outdoor VOC concentrations for School Districts A and B sourcemodified and standard classrooms operating with IDEC systems in fall cooling season. Measured values in bold text are within factor of two of predicted values.

\begin{tabular}{|c|c|c|c|c|c|c|c|c|}
\hline \multirow[b]{5}{*}{ Compound } & \multicolumn{8}{|c|}{ Concentration (ppb) } \\
\hline & \multicolumn{4}{|c|}{$\underline{\text { School District A Classroom }}^{\mathbf{a}}$} & \multicolumn{4}{|c|}{$\underline{\text { School District B Classroom }}^{\mathbf{b}}$} \\
\hline & \multicolumn{2}{|c|}{ SDA-A } & \multicolumn{2}{|c|}{ SDA-B } & \multicolumn{2}{|c|}{ SDB-A } & \multicolumn{2}{|c|}{ SDB-B } \\
\hline & & Average & & Average & & Average & & Average \\
\hline & Predicted & Measured & Predicted & Measured & Predicted & Measured & Predicted & Measured \\
\hline Phenol & 1.19 & 0.56 & 3.1 & 1.62 & 0.66 & 0.41 & 3.5 & 0.84 \\
\hline 2-Butanone & 0.11 & $<0.26$ & 0.11 & $<0.26$ & -- & $<0.26$ & -- & $<0.26$ \\
\hline Formaldehyde & -- & 4.2 & 2.8 & 9.9 & 0.50 & 12.2 & 5.1 & 6.1 \\
\hline Acetaldehyde & 1.59 & 0.64 & 3.1 & 1.79 & 2.2 & 2.2 & 5.6 & 1.50 \\
\hline Hexanal & 0.91 & $<0.84$ & 0.91 & 1.62 & -- & 1.96 & 1.73 & 2.8 \\
\hline Nonanal & 0.05 & 0.92 & -- & 1.41 & 0.07 & 1.06 & 0.17 & 2.3 \\
\hline Decanal & 0.06 & $<0.36$ & 0.16 & 0.36 & 0.05 & $<0.36$ & 0.27 & 0.40 \\
\hline Vinyl acetate & 9.7 & $<0.06$ & 28 & 0.11 & 14.3 & 0.22 & 41 & $<0.06$ \\
\hline a-Terpineol & 0.04 & $<0.01$ & 0.04 & 0.02 & -- & 0.04 & -- & 0.06 \\
\hline Toluene & 0.63 & 0.41 & -- & 0.42 & 0.93 & 1.06 & -- & 0.52 \\
\hline $1,2,4-\mathrm{TMB}^{\mathrm{c}}$ & 0.09 & 0.08 & 2.5 & 0.19 & 0.03 & 0.16 & 3.5 & 0.09 \\
\hline Naphthalene & 0.06 & 0.04 & 0.06 & 0.20 & -- & 0.07 & -- & 0.01 \\
\hline $4-\mathrm{PCH}^{\mathrm{c}}$ & -- & $<0.02$ & -- & $<0.02$ & -- & $<0.02$ & 0.06 & 0.09 \\
\hline $\mathrm{NMP}^{\mathbf{c}}$ & -- & $<0.02$ & 4.5 & 0.34 & -- & 0.06 & 6.7 & 0.91 \\
\hline Caprolactam & -- & $<0.22$ & -- & $<0.22$ & 0.28 & $<0.22$ & 4.2 & 4.8 \\
\hline
\end{tabular}

a. Design ventilation rate $790 \mathrm{~m}^{3} \mathrm{~h}^{-1}$.

b. Design ventilation rate $535 \mathrm{~m}^{3} \mathrm{~h}^{-1}$.

c. Compound abbreviations defined in Table 2 . 
Table 12. Results of paired, two-tailed $t$ test of hypothesis that there was no significant difference in adjusted indoor concentrations of VOCs between modified and standard classrooms when both were operating with IDEC systems in fall semester. Classroom concentrations on weeks two, four, six, and eight at each school were paired.

\begin{tabular}{lcccc}
\hline Compound & $\begin{array}{c}\text { Mean Diff. } \\
(\mathrm{ppb})\end{array}$ & $\begin{array}{c}\text { Number } \\
\text { Pairs }\end{array}$ & t-Value & P-Value \\
\hline Phenol & $-0.68^{\mathbf{a}}$ & 8 & -2.89 & 0.023 \\
Formaldehyde & -0.11 & 8 & -0.04 & 0.970 \\
Acetaldehyde & -0.40 & 8 & -0.62 & 0.553 \\
Hexanal & $-0.89^{\mathbf{a}}$ & 8 & -2.63 & 0.034 \\
Nonanal & $-0.84^{\mathbf{a}}$ & 8 & -3.20 & 0.015 \\
Toluene & 0.32 & 8 & 1.74 & 0.125 \\
1,2,4-TMB & -0.01 & 8 & -0.26 & 0.801 \\
Naphthalene & -0.05 & 8 & -1.05 & 0.328 \\
NMP & $-0.48^{\mathbf{a}}$ & 8 & -3.44 & 0.011 \\
Caprolactam & $-4.2^{\mathbf{a}}$ & 4 & -3.94 & 0.029 \\
& & & & \\
\hline
\end{tabular}

a. Statistically significant difference between modified and standard classrooms. b. Compound abbreviations defined in Table 2 . 
Table 13. Range of derived VOC emission factors in four classrooms eight weeks after first occupancy compared to derived emission factors from two studies of new, unoccupied manufactured houses

\begin{tabular}{|c|c|c|c|}
\hline \multirow[b]{2}{*}{ Compound } & \multicolumn{3}{|c|}{ Derived Emission Factor $\left(\mu \mathrm{g} \mathrm{m}^{-2} \mathrm{~h}^{-1}\right)$} \\
\hline & $\begin{array}{c}4 \text { Classrooms } \\
\text { Range }\end{array}$ & $\begin{array}{c}4 \text { Manuf. Houses }^{\mathrm{a}} \\
\text { GM }^{\mathrm{b}} \text { (Range) }\end{array}$ & $\begin{array}{c}1 \text { Manu. House } \\
\text { Value }\end{array}$ \\
\hline Phenol & $<2.4-3.6$ & $9.6(2.2-16.6)$ & -- \\
\hline 2-Butanone & $<5.4-7.9$ & $22(8.6-90)$ & -- \\
\hline Formaldehyde & $<23-320$ & $45(29-68)$ & $62 \pm 10$ \\
\hline Acetaldehyde & $<10.9-16.6$ & $17(6-46)$ & $26 \pm 4.4$ \\
\hline Pentanal & $<7.0$ & -- & $50 \pm 8.1$ \\
\hline Hexanal & $<37$ & $77(46-137)$ & $181 \pm 31$ \\
\hline Heptanal & $<3.5$ & $7.7(3.9-12.9)$ & $16.9 \pm 2.5$ \\
\hline Octanal & $<8.8$ & $14.1(7.4-22)$ & $29 \pm 4.4$ \\
\hline 2-Octenal & $<3.4$ & -- & $13.1 \pm 1.9$ \\
\hline Nonanal & $<25$ & $14.7(3.3-23)$ & $28 \pm 4.4$ \\
\hline$\alpha$-Pinene & $4.1-14.9$ & $105(41-189)$ & $156 \pm 25$ \\
\hline d-Limonene & $4.5-9.6$ & $18.5(9.9-36)$ & $28 \pm 4.4$ \\
\hline Toluene & $11.2-34$ & $3.9(<2.7-9.6)$ & -- \\
\hline Styrene & $1.08-2.2$ & $4.1(1.8-15.5)$ & -- \\
\hline
\end{tabular}

a. From Table 5, Hodgson et al. (2000).

b. Geometric mean (GM) and range for measurements made in four houses on three occasions over nine months after installation.

c. Calculated from Table 5, Hodgson et al. (2002); derived EFs from house measurements \pm one standard deviation. 


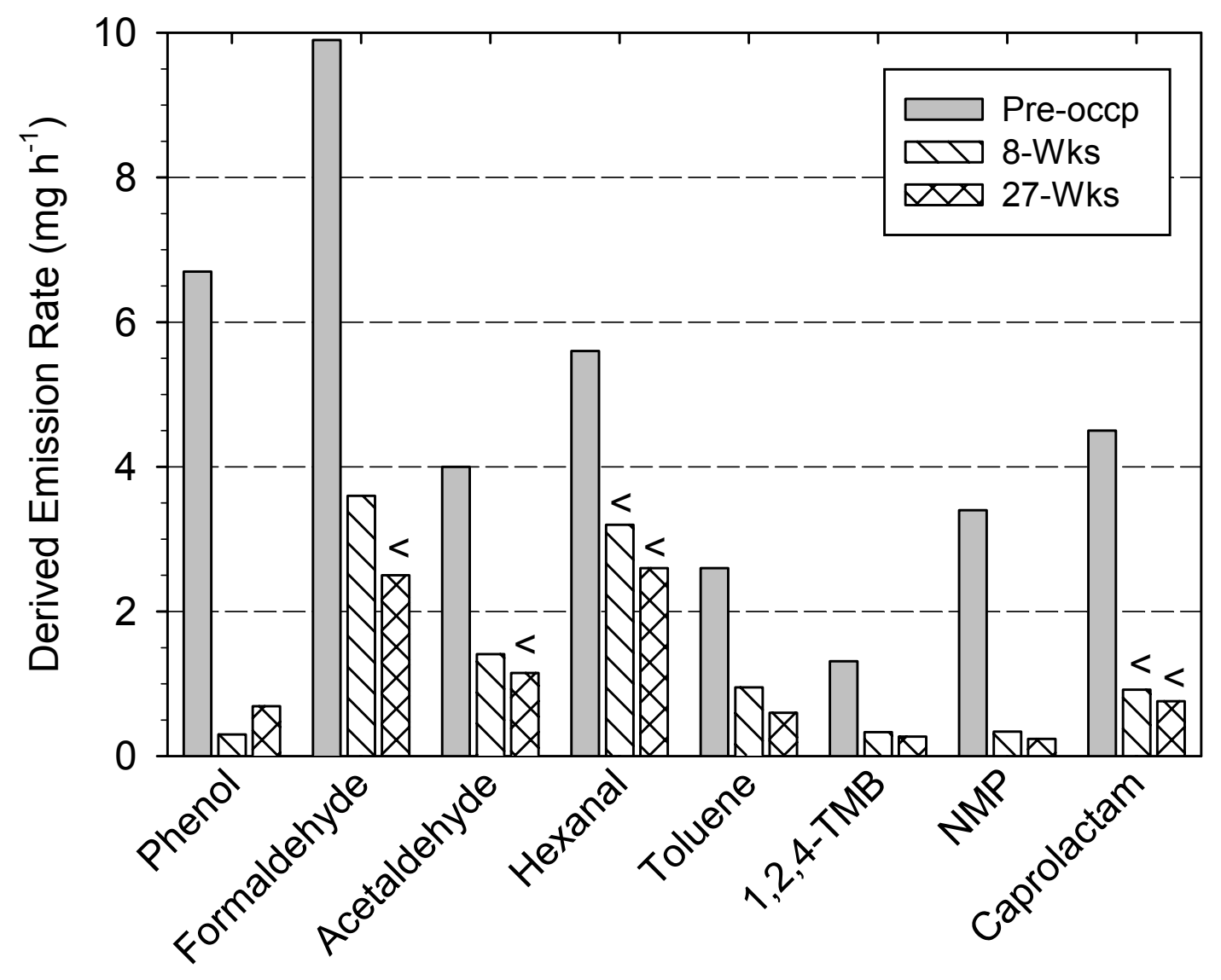

Figure 1. Derived emission rates of selected VOCs in classroom SDA-B prior to occupancy and at eight and 27 weeks after first occupancy The "<" symbols indicate values at or below the empirical lower limit of quantitation for the analysis. 


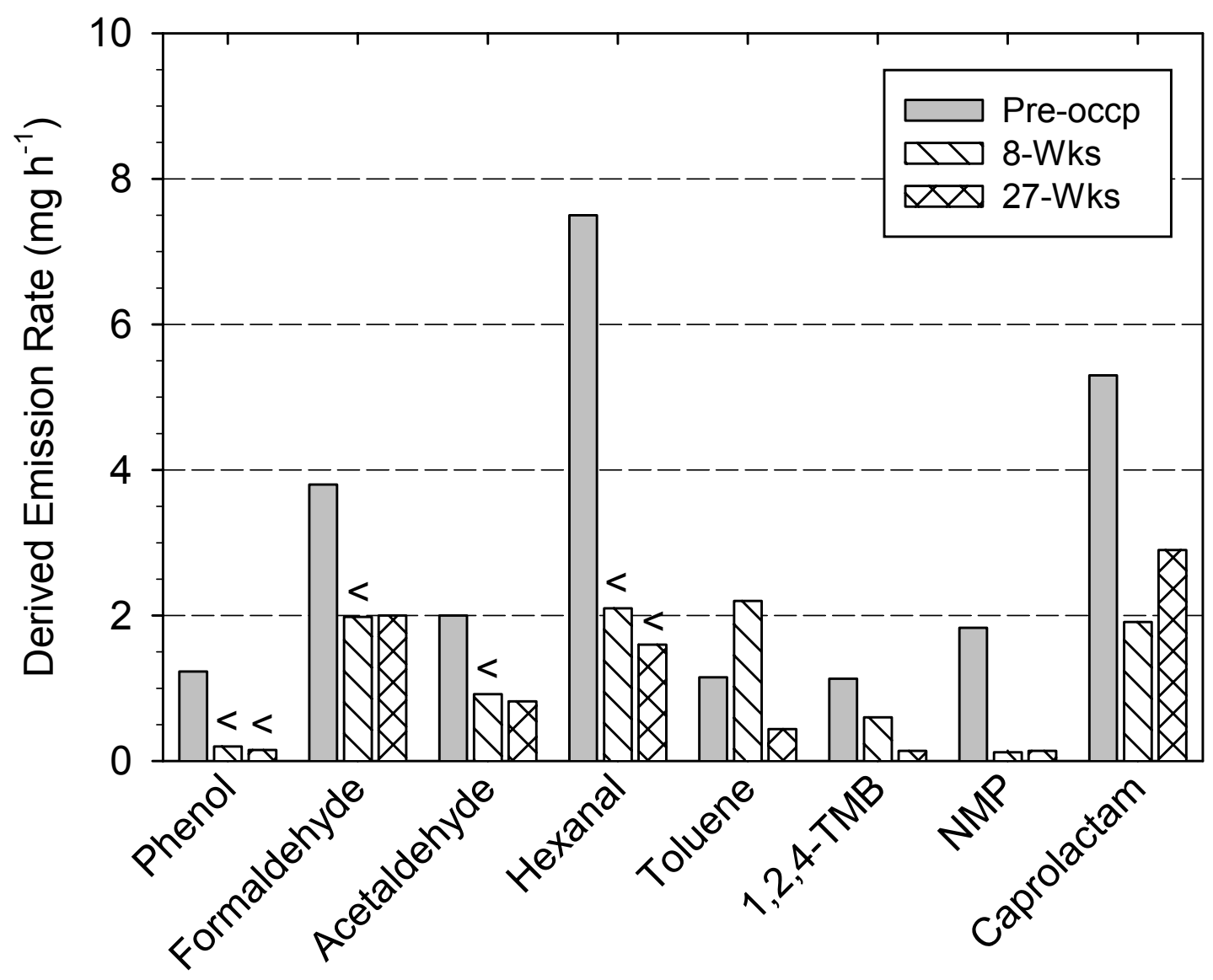

Figure 2. Derived emission rates of selected VOCs in classroom SDB-B prior to occupancy and at eight and 27 weeks after first occupancy. The " $<$ " symbols indicate values at or below the empirical lower limit of quantitation for the analysis. 